\title{
First-Generation College Students in the Israeli Periphery Contending With Challenges in an Entrepreneurship Education Program
}

\author{
Shani Kuna ${ }^{1^{*}}$ and Ronit Nadiv ${ }^{1}$ \\ ${ }^{1}$ Sapir Academic College, Israel
}

\begin{abstract}
In this ethnographic research, we explore the experiences of undergraduate first-generation students in a new academic entrepreneurship education program. Considering the marketoriented turn in academia and given the vast resources spent on entrepreneurship education, a debate has recently emerged regarding the contribution of such programs to students. We conducted semi-structured in-depth interviews with a sample of 44 students in a new annual entrepreneurship program in a college in the periphery of Israel. The students perceived a significant gap between their wish to acquire entrepreneurial skills and their self-conception as unwelcome parties in the entrepreneurial domain associated with elite groups. Consequently, these first-generation students reported low entrepreneurial intentions. Our findings indicate that despite their initial enthusiasm about entrepreneurship education, firstgeneration students experienced challenges that may hamper their chances of success as students as well as young entrepreneurs in the labor market. Although Israel may be known as "the start-up nation," entrepreneurship education is not readily accepted by all, as it can be perceived as a mechanism that exacerbates rather than alleviates geographical and economic disparities. Our study provides a critical perspective on entrepreneurship education in academic institutions. Practical implications are offered.
\end{abstract}

Keywords: entrepreneurship education, higher education, first-generation students, challenges

\section{Introduction}

As in many countries, Israeli higher education has recently witnessed a market-oriented turn in which academic institutions aspire to strengthen academia-business ties as well as to initiate the marketization of research innovations (Oliver \& Frank, 2014; Sapir \& Oliver, 2017). Consequently, academic institutions have been encouraged to integrate entrepreneurship education (EE) in their curriculum. Furthermore, considering the competition between academic institutions, they have utilized new EE programs to market academic education to prospective students. Despite their differences, academic EE programs typically aim at equipping their students with entrepreneurial skills and knowledge by 


\section{3rd International Conference on Advanced Research in Teaching and Education}

facilitating processes in which students acquire those skills combined with field experiences that expose them de facto to entrepreneurial situations and demands (Stoll \& Brown, 2019).

The mechanisms through which academic institutions might create and exacerbate inequality have been studied extensively (e.g., Gabriel, 2020) also in Israel (Abu-Rabia-Queder, 2019). Considering the market-oriented turn in Israeli academia and given the vast resources spent on novel EE programs, a debate has recently emerged regarding the role and impact of such programs on participants. While some believe that EE is a crucial contemporary component of higher education, especially among underprivileged groups, others assume that EE is another mechanism that could exacerbate disparities. Hence the purpose of our ethnographic research is to explore the experiences of undergraduate first-generation students in a novel academic entrepreneurship education program in a community college in the periphery of Israel.

\subsection{The impact of entrepreneurship education}

Since the first entrepreneurship course at Harvard University in 1947, EE in higher education has grown globally to a vast extent (Nabi et al., 2017). This growth had been attributed to several factors, including the assumption that EE has a positive impact on the entrepreneurial success of its participants. In their meta-analysis study, Nabi et al. (2017) systematically reviewed empirical evidence on the impact of $\mathrm{EE}$ in higher education on a range of entrepreneurial outcomes. In sum, they conclude that ample studies in this discipline focus on short-term and subjective impact indicators, especially entrepreneurial intentions, rather than actual entrepreneurial behavior. They stressed the scarcity of research evidence on impact indicators examining objective and higher-level measures, such as the macro-level impact of EE programs' participants on their economy and society. Given evidence implying a clear positive link between EE in higher education and entrepreneurial success, the expansion of EE programs continues (Komulainen et al., 2020; Stoll \& Brown, 2019).

\subsection{Entrepreneurship education and Inequality}

There is a debate regarding the impact of EE in higher education on social inequality. On the one hand, some consider EE in higher education to be a valuable tool for the upward mobility of minorities and underprivileged groups due to the acquisition of skills and knowledge that are valued in the labor market (Stoll \& Brown, 2019). On the other hand, evidence suggests that EE may not provide the presumed advantages. Entrepreneurial narratives presented as identity models in higher education were not equally accessed by women and lower-class students (Komulainen et al., 2020). Discourses of entrepreneurship were gendered (Jones, 2014; Westhead \& Solesvik, 2016). Furthermore, ethnic minorities experienced hardship attempting to succeed as entrepreneurs (Banerjee \& Tedmanson, 2010; Blake \& Hanson, 2005; Essers \& Tedmanson, 2014). These findings have elicited calls for a critical examination of entrepreneurship education (Berglund et al., 2020; Gaggiotti et al., 2020).

\subsection{The research context: Israel, the "start-up nation"}

Israel is known as "the start-up nation" (Senor \& Singer, 2009). The success of Israel's hi-tech sector over the past two decades has attracted ample attention from academics ae well as the popular business press. Successful Israeli innovators and prominent entrepreneurs have been repeatedly portrayed as the heroes and leaders of the Israeli economy. In this context, Israel is

\section{info@icate.org}


known for successful cases of marketization of research innovations and significant academia-business ties (Oliver \& Frank, 2014; Sapir \& Oliver, 2017).

The wealth of the hi-tech sector and the glory of its entrepreneurs, however, do not characterize all of Israel's regions but only its center: the economic capital Tel Aviv and its metropolitan area. The Israeli geographical periphery is typically associated with poverty and educational disparities. Over the years, a sharp hierarchy in the stratification system has become institutionalized in the Israeli labor market. Neoliberalism has intensified income inequalities besides exacerbating the marginalization of minorities in the Israeli labor market (Mundlak, 2017). Considering the acute economic tensions between the Israeli center and periphery, a community college in the Israeli periphery provides a fascinating setting for exploring the notion of a novel EE program among first-generation college students.

In the following section, we specify our methodological approach. Then we present our findings. In the final section, we discuss our findings as well as their potential consequences for undergraduate students and for higher education in general. Practical implications are offered.

\section{Method}

\subsection{Sample}

A novel EE program operated during the 2019-2020 year in an academic community college in the periphery in Israel. The program was based on the principles and methodology of The lean start-up (Ries, 2011). Participation in the annual program entitled the students to academic credit. The participants in our study were 40 (20 women, 20 men) first-generation undergraduate students who had chosen to participate in the annual entrepreneurship program. The participants responded to our written invitation regarding the research that was sent by email to all 150 students in the EE program. Their average age was 29 , and $85 \%$ of them were single.

\subsection{Data Collection}

A grounded theory approach was utilized (Creswell \& Poth, 2017). We conducted semistructured in-depth interviews individually with each participant. Several predetermined questions that were presented to each participant explored their conceptions of the entrepreneurship program. Additional relevant topics raised by the interviewees prompted further inquiry. Semi-structured in-depth interviews were utilized to facilitate participants' detailed descriptions of their daily experiences as student entrepreneurs. This method of study has allowed us to understand how the participants construct and negotiate their identity in terms of students who are grappling with the academic and practical tasks and demands of the program.

The interviews lasted about 90 minutes on average. All interviewees gave their informed consent to participate in the study and were assured confidentiality. All interviews were audio recorded and transcribed verbatim.

\subsection{Data Analysis}

info@icate.org 


\section{3rd International Conference on Advanced Research in Teaching and Education}

In the subsequent phase of thematic content analysis, guided by Creswell and Poth (2017), each of the authors coded each interview separately, The first round of coding yielded several categories, such as identity conflicts, benefits of entrepreneurship education, and more. In each interview, codes were assigned to units of several sentences or entire paragraphs. Each interview yielded coded categories and illustrative quotations, which were then analyzed to discover major recurring and systematic content themes. The authors then compared their interpretations in a circular process, in which more significant codes emerged. Further analysis assisted in narrowing down the categories into several major themes. Finally, the authors analyzed the interactions between the different themes and their possible meanings. This systematic process continued until all the data was analyzed thoroughly.

\section{Findings}

\subsection{Students' motivation for participation in the EE program}

The students in the sample had initially expressed enthusiasm regarding the entrepreneurship program in light of its novelty as well as the positive image of entrepreneurship and entrepreneurs in Israel. In addition, as first-generation students, they considered this program to enhance their employability as academics after graduation. This issue was reported as significant by our interviewees, in light of the fact that they live in a geographical and economic periphery in which employment opportunities are relatively scarce.

\subsection{The challenges encountered by students in the EE program}

The students in our study perceived a significant gap between their wish to acquire entrepreneurial skills and their self-conception as unwelcome parties in the entrepreneurial domain associated with elite groups. Social class differences between the center and periphery generated identity conflicts for these first-generation college students who were already underprivileged with respect to access to social capital associated with the center and with elite hegemonic groups. The students also conceived social capital to be a prerequisite for their entrepreneurial success in the Israeli labor market. Consequently, these first-generation students reported low entrepreneurial intentions.

\section{Discussion}

Through the analysis of semi-structured interviews with a sample of participants, our aim was to decipher the challenges that first-generation students encounter in a new entrepreneurship education program in a college in the periphery of Israel. In sum, despite their initial enthusiasm, first-generation students experienced challenges that hampered their chances of success as students as well as young entrepreneurs. Although Israel may be known as "the start-up nation," entrepreneurship education is not readily accepted by all, as it can be perceived as a mechanism that exacerbates rather than alleviates geographical and economic disparities.

Our findings echo previous critical findings regarding EE (Berglund et al., 2020; Gaggiotti et al., 2020; Komulainen et al., 2020). Considering the debate regarding the role of EE in higher 


\section{3rd International Conference on Advanced Research in Teaching and Education}

education, our study suggests that EE may function as a mechanism through which academic institutions create and exacerbate inequality.

We offer practical implications. Our findings shed light on the faculty's role in assisting their students to contend with self-doubts and problems that they encounter as participants in EE programs. The tutors' early recognition of their students' hardship may advance students' success in entrepreneurship programs as well as following graduation upon joining the labor force.

\subsection{Limitations and suggestions for future research}

This exploratory qualitative study has some limitations. First, it was based on a medium-sized sample of students who expressed their willingness to be interviewed. Second, we have not included a comparison to students in EE programs in other academic institutions in Israel. Finally, this study focused on students' perceptions and did not obtain quantitative data.

Future research may overcome the limitations of this study and delve further into an intriguing array of issues: Do specific organizational or environmental circumstances trigger different types of challenges among college students in EE programs? What other factors may foster students' success in EE programs? It is our hope that future research will endeavor to provide necessary insights for this discipline.

\section{Conclusion}

In this article, we have explored the experiences of first-generation undergraduate students in an entrepreneurship education program in a college in the Israeli periphery. While EE has recently become a more common component of higher education, our study demonstrates that is could be perceived by first-generation students in the periphery as a mechanism that exacerbates rather than alleviates geographical and economic disparities. 


\section{3rd International Conference on Advanced Research in Teaching and Education}

\section{References}

Abu-Rabia-Queder, S. (2019). The paradox of diversity in the Israeli academia: reproducing white Jewishness and national supremacy, Race Ethnicity and Education, DOI: 10.1080/13613324.2019.1694502

Ahl, H., \& Marlow, S. (2012). Exploring the dynamics of gender, feminism and entrepreneurship: Advancing debate to escape a dead end? Organization, 19(5), 543-562.

Ahl, H., \& Nelson, T. (2015). How policy positions women entrepreneurs: A comparative analysis of state discourse in Sweden and the United States. Journal of Business Venturing, 30(2), 273-291.

Banerjee, S., \& Tedmanson, D. (2010). Grass burning under our feet: Indigenous enterprise development in a political economy of whiteness. Management Learning, 41(2), 147-165.

Blake, M. K., \& Hanson, S. (2005). Rethinking innovation: context and gender. Environment and Planning A, 37(4), 681-701.

Berglund, K., Verduijn, K. (Eds.). (2018). Revitalizing entrepreneurship education. Adopting a critical approach in the classroom. Routledge.

Berglund, K., Hytti, U., \& Verduijn, K. (2020). Editorial: Unsettling entrepreneurship education. Entrepreneurship Education and Pedagogy, 3(3), 208-213.

Calas, M. B., Smircich, L., \& Bourne, K. A. (2009). Extending the boundaries: Reframing "entrepreneurship as social change" through feminist perspectives. Academy of Management Review, 34(3), 552-569.

Creswell, J.W., \& Poth, C.N. (2017). Qualitative inquiry and research design. Sage.

Essers, C., \& Tedmanson, D. (2014). Upsetting 'others' in the Netherlands: Narratives of Muslim Turkish migrant businesswomen at the crossroads of ethnicity, gender and religion. Gender, Work \& Organization, 21(4), 353-367.

Gabriel, D. (2020). Transforming the ivory tower: Models for gender equality and social justice. UCL Press.

Gaggiotti, H., Jarvis, C., \& Richards, J. (2020). The texture of entrepreneurship programs: Revisiting experiential entrepreneurship education through the lens of the LiminalLiminoid continuum. Entrepreneurship Education and Pedagogy, 3(3), 236-264.

Jones, S. (2014). Gendered discourses of entrepreneurship in UK higher education: The fictive entrepreneur and the fictive student. International Small Business Journal, 32(3), 237-258.

Nabi, G., Liñán, F., Fayolle, A., Krueger, N., \& Walmsley, A. (2017). The impact of entrepreneurship education in higher education: A systematic review and research agenda. Academy of Management Learning \& Education, 16(2), 277-299.

Komulainen, K., Siivonen, P., Kasanen, K., \& Räty, H. (2020). "How to give a killer pitch?" Performances of entrepreneurial narratives as identity models in higher education. Entrepreneurship Education and Pedagogy, 3(3), 214-235. 


\section{3rd International Conference on Advanced Research in Teaching and Education}

Mundlak, G. (2017). Contradictions in Neoliberal reforms: The regulation of labor subcontracting. In A. Maron \& M. Shalev (eds.), Neoliberalism as a state project: Changing the political economy of Israel (pp. 153-171). Oxford: Oxford University Press.

Neck, H. M., \& Corbett, A. C. (2018). The scholarship of teaching and learning entrepreneurship. Entrepreneurship Education and Pedagogy, 1(1), 8-41.

Oliver, A., \& Frank, N. (2014). Israel's knowledge-intensive sectors: Innovation, networks and regions. In B. Aharonson, U. Stettner, T.L. Amburgey, S. Ellis, \& I. Drori (eds). Understanding the relationship between networks and technology, creativity and innovation (pp. 37-64). Emerald.

Ozkazanc-Pan, B. (2014). Postcolonial feminist analysis of high-technology entrepreneuring. International Journal of Entrepreneurial Behavior \& Research, 20(2), 155-172.

Ries, E. (2011). The lean start-up. Crown Publishing.

Sapir, A. \& Oliver, A. L. (2017). From academic laboratory to the market: Disclosed and undisclosed narratives of commercialization. Social Studies of Science, 47(1), 52-33.

Senor, D. \& Singer, S. (2009). The start-up nation. Hachett Book Group.

Steyaert, C., \& Katz, J. (2004). Reclaiming the space for entrepreneurship in society: Geographical, discursive and social dimensions. Entrepreneurship \& Regional Development, 16(3), 179-196.

Stoll, A., \& Brown, J. N. (2019). Community colleges as incubators of innovation: Unleashing entrepreneurial opportunities for communities and students. Stylus Publishing.

Talmage, C. A., \& Gassert, T. A. (2020). Unsettling entrepreneurship by teaching Dark Side Theories. Entrepreneurship Education and Pedagogy, 3(3), 316-345.

Tedmanson, D., Verduyn, K., Essers, C., \& Gartner, W.B. (2012). Critical perspectives in entrepreneurship research. Organization, 19(5), 531-541.

Welter, F., Baker, T., Audretsch, D.B., \& Gartner, W.B. (2016). Everyday entrepreneurship: A call for entrepreneurship research to embrace entrepreneurial diversity. Entrepreneurship Theory and Practice, 41(3), 311-321.

Westhead, P., \& Solesvik, M. Z. (2016). Entrepreneurship education and entrepreneurial intention: do female students benefit? International Small Business Journal, 34(8), 9791003. 